\title{
Uranium exposure increases spermatocytes metaphase apoptosis in rats: inhibitory effect of thymoquinone and $\mathrm{N}$-acetylcysteine
}

\author{
Hanan Waly ${ }^{1}$, Sohair M. M. Ragab ${ }^{1}$, Khaled M. A. Hassanein ${ }^{2,3}$, Nasser S. Abou Khalil ${ }^{4}$ \\ and Emad A. Ahmed ${ }^{5,6}$ \\ ${ }^{1}$ Laboratory of Physiology, Department of Zoology, Faculty of Sciences, Assiut University, Assiut, Egypt \\ ${ }^{2}$ Department of Pathology and Clinical Pathology, Faculty of Veterinary Medicine, Assiut University, Assiut, Egypt \\ ${ }^{3}$ Deanship of Scientific Research, Jazan University, Jazan, Saudi Arabia \\ ${ }^{4}$ Department of Medical Physiology, Faculty of Medicine, Assuit University, Assiut, Egypt \\ ${ }^{5}$ Department of Biological Science, Faculty of Science, King Faisal University, Hofouf, Saudi Arabia \\ ${ }^{6}$ Laboratory of Immunology and Molecular Physiology, Department of Zoology, Faculty of Science, Assiut University, Assiut, \\ Egypt
}

\begin{abstract}
Uranyl acetate (UA), a commercial stock from depleted uranium (DU), has a combined effect of chemical toxicity and mild radioactivity. Here, we investigated the potential antioxidant, antiapoptotic and cytoprotective effects of thymoquinone (TQ) and N-acetylcysteine (NAC) against UA-induced testicular damage in rats. UA reduced testicular superoxide dismutase (SOD) activity and nitric oxide (NO) and glutathione (GSH) levels relative to the control group. Interestingly, the testicular SOD activity and NO and GSH levels of UA/TQ- and UA/NAC-treated groups were also significantly lower relative to the control. A marked increase in spermatocytes metaphase apoptosis was found (stage XIII) in UA-treated rats, which is probably due to difficulties in segregation of homologous-chromosomes. This may clarify why UA exposure decreased round spermatids numbers and fertility in previous studies. To check the reason of partial metaphase arrest, the presence of DNA-damage-related $\gamma$-H2AX foci in late spermatocytes of all groups was checked, but only insignificant increase was found in UA-treated group. TQ or NAC supplementation reduced the apoptosis and improved the testicular histological alterations. Thus, TQ and NAC attenuate UA adverse effects on the testicular microenvironment through anti-apoptotic and cytoprotective but not antioxidant effects.
\end{abstract}

Key words: Uranyl acetate - Testis - Metaphase apoptosis - Thymoquinone - N- Acetylcysteine

\begin{abstract}
Abbreviations: DU, depleted uranium; GSH, glutathione; HO-1, heme oxygenase-1; LPO, lipid peroxidation; NAC, $\mathrm{N}$-acetylcysteine; NO, nitric oxide; $\mathrm{POD}$, peroxidase; $\mathrm{SAC}$, spindle assembly check-point; SOD, superoxide dismutase; TBARS, thiobarbituric acid reactive substances; TQ, thymoquinone; UA, Uranyl acetate.
\end{abstract}

Correspondence to: Nasser S. Abou Khalil, Department of Medical Physiology, Faculty of Medicine, Assuit University, Assiut, Egypt E-mail: nassersayednassers@yahoo.com

Emad A. Ahmed, Department of Biological Science, Faculty of Science, King Faisal University, Hofouf, Saudi Arabia

E-mail: aahmed@kfu.edu.sa emad.ahmed@science.aun.eg

\section{Introduction}

Depleted uranium (DU), a waste product of uranium enrichment, is widely used in several human activities and is associated with multiple health problems (Bleise et al. 2003; Di Lella et al. 2005). Uranium persists for long period at the bio-ecological systems because of its long half-life time, various ways of exposure, magnification through the food chain, 
and combined metallic and radiation toxicities (Di Lella et al. 2005; Briner 2010). Several chelating ligands have been used to hasten the urinary exertion of uranium and to reduce its toxicity (Jin et al. 2016; Swami and Shrivastava 2016) but unfortunately, this therapeutic strategy faced many problems including exaggeration of the DU nephrotoxicity and the in vivo blockage of detoxification pathways (Briner 2010; Hao et al. 2016). Unexpected lack of deleterious physiological effects was seen in rats after a chronic oral intake, for 9 months to mimic the chronic exposure of uranium-rich territories inhabitants (Dublineau et al. 2014). Therefore, finding agents with powerful ameliorative influences against the radiological hazards of DU with potential natural biological occurrence and wide toxic-therapeutic window represents area of increasing interest.

Testis is one of the main target organs that is exposed to DU due to the ability of UA to pass through and negatively impact the blood testis barriers (Legendre et al. 2016). Nevertheless, conflict data emerged regarding the potential reproductive health burden of UA relative to radiological activities of the compound, wide range of variations in the dose and route of exposure, and differential responses of the strain and age of challenged animals (Llobet et al. 1991; Arfsten et al. 2009; Li et al. 2009; Legendre et al. 2016). DU did not markedly influence the testicular steroidogenesis in rats, however the enriched UA significantly increased the level of circulating testosterone and up-regulated the gene expression involved in its metabolism (Grignard et al. 2008). Lifelong intoxication with low doses of DU in rats from embryonic stage to adulthood through drinking water induced disturbances in the testicular steroidogenesis by acting through the hypothalamic-pituitary-testicular axis, but without causing major testicular histoarchitecture defects (Legendre et al. 2016). Interestingly, previous histopathological examinations revealed few differences in the tubules and germ cells of uranium-exposed and control animals (Llobet et al. 1991; Linares et al. 2005). A significant (not dose-related) decrease in the pregnancy rate, after mating male mice exposed to UA in drinking water $(10-40 \mathrm{mg} /$ $\mathrm{kg} / \mathrm{b} . \mathrm{w}$.) for two weeks associated with a significant decrease in spermatid number/testis have been found (Linares et al. 2005). However, long-term exposure to uranium induced reproductive toxicity through different mechanisms of action including inflammation, testicular degeneration, vacuolization of Leydig cells and spermatocytes necrosis (reviewed in Asghari et al. 2015).

Shifting oxidant/antioxidant balance towards the prooxidant side is the possible mechanistic way lies behind the testicular UA toxicity by depletion of glutathione redox system and down-regulation of inducible nitric oxide synthase gene expression (Li et al. 2005; Linares et al. 2006). Thymoquinone (TQ) and N-acetylcysteine (NAC) in this issue are highly promising candidates owing to their antioxi- dant and anti-apoptotic properties (Kilciksiz et al. 2008; Li et al. 2015; Guida et al. 2016; Hassanein and El-Amir 2017) giving a solid-based rationality to interfere with multiple toxicological targets of DU. Both of TQ and NAC have been suggested as upstream regulators of the antioxidant enzyme, heme oxygenase-1 (HO-1) by inducing its expression which suppresses inflammation and carcinogenesis (Yi and Hazell 2005; Kundu et al. 2014). Because of its antioxidant and anti-inflammatory activities, TQ was found to increase the healthy sperm number and protects from testicular injury (Fouad and Jresat 2015; Tüfek et al. 2015) suggesting that it is an ideal testicular protective agent. TQ in this field is considered as a one of not fully researched radiationmodifying agents which needs further investigation to cover its protective abilities in different types of radiations and irradiated organs along with exploring its mechanistic action. A previous report showed that TQ exhibited protective effects against nitrosative damage in the brain of rats exposed to gamma radiation by reducing nitric oxide (NO) and peroxynitrite levels and NO synthase activity (Ahlatci et al. 2014). An evidence came from a study focused on T lymphocytes balance in gamma irradiated rats illustrating a marked decrease in $\mathrm{T}$ cell exhaustion and apoptosis following TQ supplementation by modulating the expression of pro- and anti-apoptotic markers and pro-inflammatory cytokines (Guida et al. 2016). However, the ways by which UA and gamma radiation evoked testicular toxicity have faces of both differences and similarities. Both of UA and gamma radiation induced genotoxicity, oxidative stress, and histopathological lesions in the seminiferous tubules and Leydig cells. However, UA has inflammatory properties, while gamma radiation contribute to testicular dysfunction by interfering with cellular antioxidant protective system, changing mitochondrial electron transport chain, and stimulating apoptotic pathway mediators (Aitken and Roman 2008; Azzam et al. 2012; Hossein Asghari et al. 2015; Khan et al. 2015; Szumiel 2015; Marzban et al. 2017).

Being an analog and a precursor for intracellular glutathione (GSH), NAC is very effective in replenishing tissue GSH content which plays a key role in enhancing the antioxidant defense mechanism against radiation injury (Chatterjee 2013; Li et al. 2015). Several types of somatic and germ cells have a high GSH content including Sertoli and peritubular cells, pachytene spermatocytes, round spermatids, and interstitial tissue (Bauché et al. 1994). NAC alleviated the radiation challenges on hippocampus, bone marrow and liver by inhibiting lipid peroxidation, stimulating redox buffer systems, and down-regulating caspase-3 gene expression (Kilciksiz et al. 2008; Demİrel et al. 2009; $\mathrm{Li}$ et al. 2015). However, there is no available information yet about the potential radioprotective effects of TQ or NAC on UA irradiated testis, therefore the aim of this study is to investigate this issue through monitoring the changes 
in the oxidant/antioxidant balance, DNA fragmentation and histopathological features in the testes of Sprague Dawley rats.

\section{Materials and Methods}

\section{Animals and experimental groups}

More than forty male Sprague Dawley rats at 6-8 weeks of age obtained from the Animal House, Faculty of Medicine, Assuit University, Assiut, Egypt, and bred under controlled conditions with $12 \mathrm{~h}$ light/dark cycle, a temperature of $23^{\circ} \mathrm{C}$ and a relative humidity of $55 \%$. Food and water were provided ad libitum. After acclimatization period of 5 days, rats weighing 180-200 g were selected for the experiment. Rats were randomly and equally divided into four groups, 10 rats each (5 rats per cage). One group was injected intraperitoneally with distilled water and kept as a control, while the second group was injected intraperitoneally with a single dose of UA (1 mg/kg b.w.) (Barber et al. 2005). Because uranyl ions are the most stable types of uranium in solution and mammalian body fluids, uranium was administrated as UA (Legendre et al. 2016). The third and fourth groups were injected with the above mentioned dose of UA followed by oral administration of TQ at a dose of 20 $\mathrm{mg} / \mathrm{kg}$ b.w. (Badr et al. 2013) and intraperitoneal injection of NAC at a dose of $100 \mathrm{mg} / \mathrm{kg}$ b.w. (Prakash and Kumar 2009) for 25 days. The protocol was carried out according to the National Institute of Health Guide for Care and Use of Laboratory Animals.

\section{Samples collection}

At the end of the experiment, after 25 days of injecting UA, rats from the different groups were killed by cervical dislocation. Testes were quickly removed and one testis fixed in $10 \%$ neutral buffered formalin for histological investigation. The other testis was stored at $-20^{\circ} \mathrm{C}$ to be used for determination of oxidant/antioxidant markers. To prepare $10 \% \mathrm{w} / \mathrm{v}$ homogenate, testis was homogenized in $0.1 \mathrm{M}$ phosphate buffer (pH 7.4) using IKA Yellow line DI homogenizer (18 Disperser, Germany). The homogenates were centrifuged at $8000 \mathrm{rpm}$ for $15 \mathrm{~min}$ at $4^{\circ} \mathrm{C}$, and the supernatant cytosols were kept frozen at $-20^{\circ} \mathrm{C}$ for the subsequent biochemical assays.

\section{Biochemical measurements}

In the supernatant of testicular homogenate, total protein concentration was determined by the method of Lowry et al. (1951). Lipid peroxidation products (LPO) as thiobarbituric acid reactive substances (TBARS) were estimated according to the method of Ohkawa et al. (1979). NO was measured as nitrite concentration colorimetrically using the method of Ding et al. (1988). The activity of superoxide dismutase (SOD) was determined according to its ability to inhibit the autoxidation of epinephrine in alkaline medium according to the method of Misra and Fridovich (1972). Glutathione (GSH) content was determined using the method of Beutler et al. (1963).

\section{Histopathological examination}

Specimens from the testicular tissues were fixed in formalin buffer, dehydrated in a series of ethyl alcohol, cleared in xylene, and then embedded in paraffin. Four micron sections were cut, stained with haematoxyline and eosin (H\&E), and examined by the light microscope.

\section{TUNEL assay}

TUNEL assay was done to check apoptosis in 5-7- $\mu \mathrm{m}$ paraffin embedded testis (Ahmed et al. 2013) according to the manufacturer's protocol (In Situ Cell Death Detection Kit, POD; Roche Diagnostics GmbH, Germany). The kit includes Converter-POD:anti fluorescein antibody, Fab fragment conjugated with peroxidase (POD), thus it was possible to visualize the apoptotic signal with DAB staining and also in fluorescent color.

\section{Immunofluorescence and immunohistochemistry}

In order to check whether uranium exposure induces persistent damage in testicular cells or not, immunostaining was performed as described earlier (Ahmed et al. 2017). Rabbit anti $\gamma$-H2AX (dil1:500, Millipore) and mouse anti 53BP1 (1:300, Novus Biologicals ) primary antibodies were diluted in PBS, $0.1 \%$ Tween 20, 0.2\% BSA, and 1\% Milk powder. The 2ry antibodies used were HRP goat anti-rabbit (dil1:500, DAKo) or goat anti-rabbit (488, dil1:500, Alexa flour), and Cy3 goat anti-mouse (Alexa Flour 546). Preparations were mounted in Vectashield (Vector Labs) containing $0.5 \mathrm{mg} /$ ml DAPI (Sigma) to stain nuclear DNA.

\section{Statistical analysis}

Data were represented as mean \pm SEM. The results were analyzed by one-way analysis of variance (ANOVA) followed by Duncan posthoc test using SPSS program version 16 (SPSS Inc., Chicago, USA). Differences of $p<0.05$ were considered to be statistically significant. One-way ANOVA had been used to examine the differences between the various experimental groups using the difference in group as an independent factor and the change in the assessed parameter as a dependent factor. 
Table 1. Effects of TQ and NAC on the oxidant/antioxidant markers in the testicular homogenate of UA intoxicated rats

\begin{tabular}{lcccc}
\hline \multirow{2}{*}{ Parameter } & \multicolumn{3}{c}{ Group } \\
\cline { 2 - 5 } & Control & UA & UA/TQ & UA/NAC \\
\hline LPO (nmol/mg protein) & $1.00 \pm 0.265^{\mathrm{a}}$ & $0.796 \pm 0.206^{\mathrm{a}}$ & $0.586 \pm 0.098^{\mathrm{a}}$ & $0.928 \pm 0.154^{\mathrm{a}}$ \\
NO (nmol/mg protein) & $0.035 \pm 0.005^{\mathrm{a}}$ & $0.019 \pm 0.002^{\mathrm{b}}$ & $0.015 \pm 0.001^{\mathrm{b}}$ & $0.025 \pm 0.003^{\mathrm{a}, \mathrm{b}}$ \\
SOD (U/mg protein) & $7.815 \pm 0.666^{\mathrm{a}}$ & $4.679 \pm 0.648^{\mathrm{b}}$ & $4.665 \pm 0.318^{\mathrm{b}}$ & $4.959 \pm 0.269^{\mathrm{b}}$ \\
GSH (nmol/mg protein) & $177.57 \pm 48.341^{\mathrm{a}}$ & $64.846 \pm 6.984^{\mathrm{b}}$ & $64.191 \pm 10.853^{\mathrm{b}}$ & $59.917 \pm 2.654^{\mathrm{b}}$ \\
\hline UA,
\end{tabular}

UA, uranyl acetate; TQ, thymoquinone; NAC, N-acetyl cysteine; LPO, lipid peroxidation; NO, nitric oxide; SOD, superoxide dismutase; $\mathrm{GSH}$, reduced glutathione. Results are represented as means $\pm \operatorname{SEM}\left(n=10\right.$ rats/group). ${ }^{\mathrm{ab}}$ different letters indicate significant difference at $p<0.05$ (one-way ANOVA followed by Duncan posthoc test).

\section{Results}

\section{Oxidant/antioxidant balance}

In the present study, UA caused a marked disturbance in the free radicals/antioxidants balance in testes of rats manifested by significant reductions in SOD activity and NO and GSH levels as compared with the control group. However, there were insignificant changes in LPO levels in the UA intoxicated group versus the unexposed one. Surprisingly, the testicular SOD activity and NO and GSH levels in all treated groups were significantly lower than those of the control group (Table 1). Thus, the studied therapeutic strategies failed to modulate the testicular oxidant/antioxidant balance induced in UA irradiated rats.

\section{Histopathological examination}

The testicular tissues of control rats showed normal seminiferous tubules displaying the different stages of spermatogenesis (Fig. 1A). Examination of the histopathological sections showed that UA caused alterations in the blood vessels and the stages of spermatogenesis. Vascular alteration included interstitial edema with pale acidophilic material (Fig. 1A).

Table 2. Incidence of the histopathological lesions in testes of the experimental groups

\begin{tabular}{lcccc}
\hline \multirow{2}{*}{ Lesion } & \multicolumn{4}{c}{ Group } \\
\cline { 2 - 5 } & Control & UA & UA/TQ & UA/NAC \\
\hline Congestion & - & +++ & - & + \\
Interstitial edema & - & +++ & - & + \\
Testicular degeneration & - & ++ & - & - \\
Necrosis & - & ++ & - & - \\
\hline
\end{tabular}

UA, uranyl acetate; TQ, thymoquinone; NAC, N-acetyl cysteine; - null lesions; + presence lesion in 1-3 rats; ++ presence lesion in $4-6$ rats; +++ presence lesion in $7-10$ rats.
The blood vessels were congested (Fig. 1B). Degenerative changes extended to necrosis were observed in some seminiferous tubules (Fig. 1D). Histological examination of the testicular tissues of TQ-treated group showed normal appearance (Fig. 1E), while the testes in NAC-treated group revealed normal appearance with minor changes as congestion and edema (Fig. 1F). The histopathological lesions score of different groups are listed in Table 2.

\section{Uranium exposure increases spermatocytes metaphase apoptosis}

Stage XIII in rat's seminiferous tubules is the stage during which diplotene spermatocytes divide (meiosis I) to give 2ry spermatocytes which in turn divide (meiosis II) at stage XIV to give the early round spermatids that appear in stage I. To check checkpoint activation in the testes of treated rats (metaphases I and II), we stained the testicular tissue sections of all groups for apoptosis using the TUNEL assay (Figs. 2 and 3). Staging of seminiferous epithelium cross section in rats has been done according to Russell et al. (1990). As illustrated in Figure 3E, the frequency of apoptotic cells in testes of UA treated rats in the stage XIII was significantly higher relative to the control and other treated groups (around 7 apoptotic nuclei per epithelial stage) probably indicating difficulties in segregation of homologous chromosomes during metaphase I (Fig. 3B). However, there were apoptotic spermatogonia (cells located at the boundaries of seminiferous epithelium) in UA, UA/TQ and UA/NAC treated groups (Fig. 2F). Quantification of these cells in 45 tubules from 3 rats per group revealed no clear vacation between treated groups (Fig. 3F).

\section{Uranium exposure induces no obvious persistent damage related foci in spermatocytes}

To further investigate the reason of an activated spindle assembly check-point (SAC) during metaphase I, we examined the presence of $\gamma$-H2AX foci at late spermatocytes in 
testicular sections stained for antibodies against the DSBs marker $\gamma$-H2AX. Data showed that some spermatocytes of UA-treated group displayed $\gamma-\mathrm{H} 2 \mathrm{ax}$ foci indicating persistent damage at only few spermatocytes (Fig. 4B). Quantification of cells with foci has shown that there was insignificant increase in \% of cells with clear foci (1-3) in UA groups (Fig. $4 \mathrm{E})$. This indicates that exposure to UA does not induce obvious persistent damage related foci at spermatocytes. However, the pronounced increase in metaphase I apoptosis could be due to improper DSB repair during the meiotic recombination of UA-treated group.

Double immunostaining of testicular sections with both another DSB marker, 53BP1 and TUNEL assay (Fig. 4C, D) revealed that apoptotic metaphase cells are negative for 53BP1. Then, the cytotoxic effect of UA might be a direct effect on metaphase check point or it is possible that the earlier improper repair has led to this partial metaphase arrest.

\section{Discussion}

In the current study, a single dose of UA caused testicular toxicity, which was evident by the reduction of the testicular GSH and NO levels and SOD activity, the activation of the metaphase check point at epithelial cycle stage XIII and
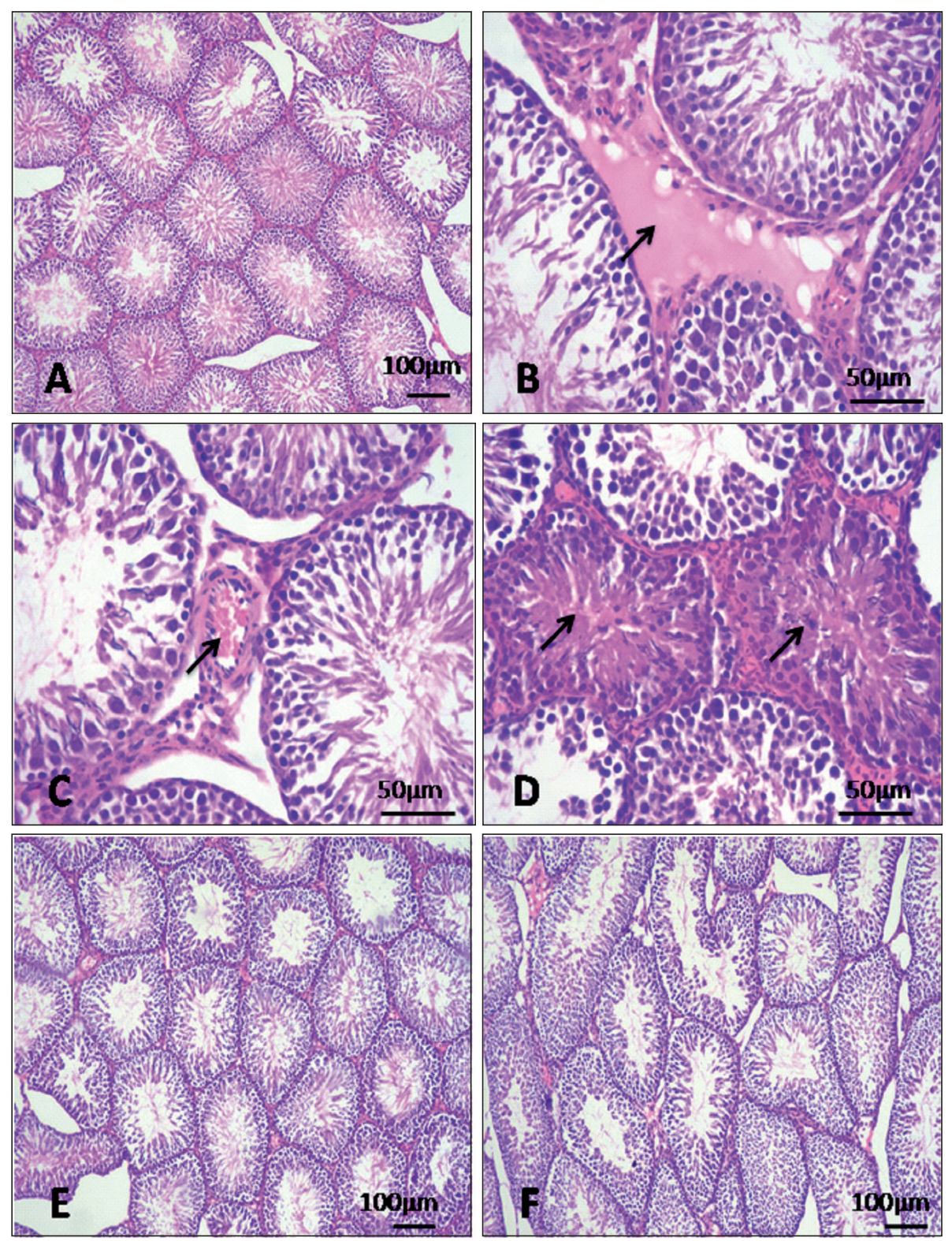

Figure 1. A. Testis of control rats showing normal histological architecture. Testis of UA-treated group showing interstitial edema (arrow, B), congestion (arrow, C), necrosis of seminiferous tubules (arrows, D). E. Testis of TQ-treated group demonstrating normal histology. F. Testis of NAC-treated group demonstrating normal histology as well as edema in the interstitial tissue (arrow). UA, uranyl acetate; NAC, Nacetylcysteine; TQ, thymoquinone. 

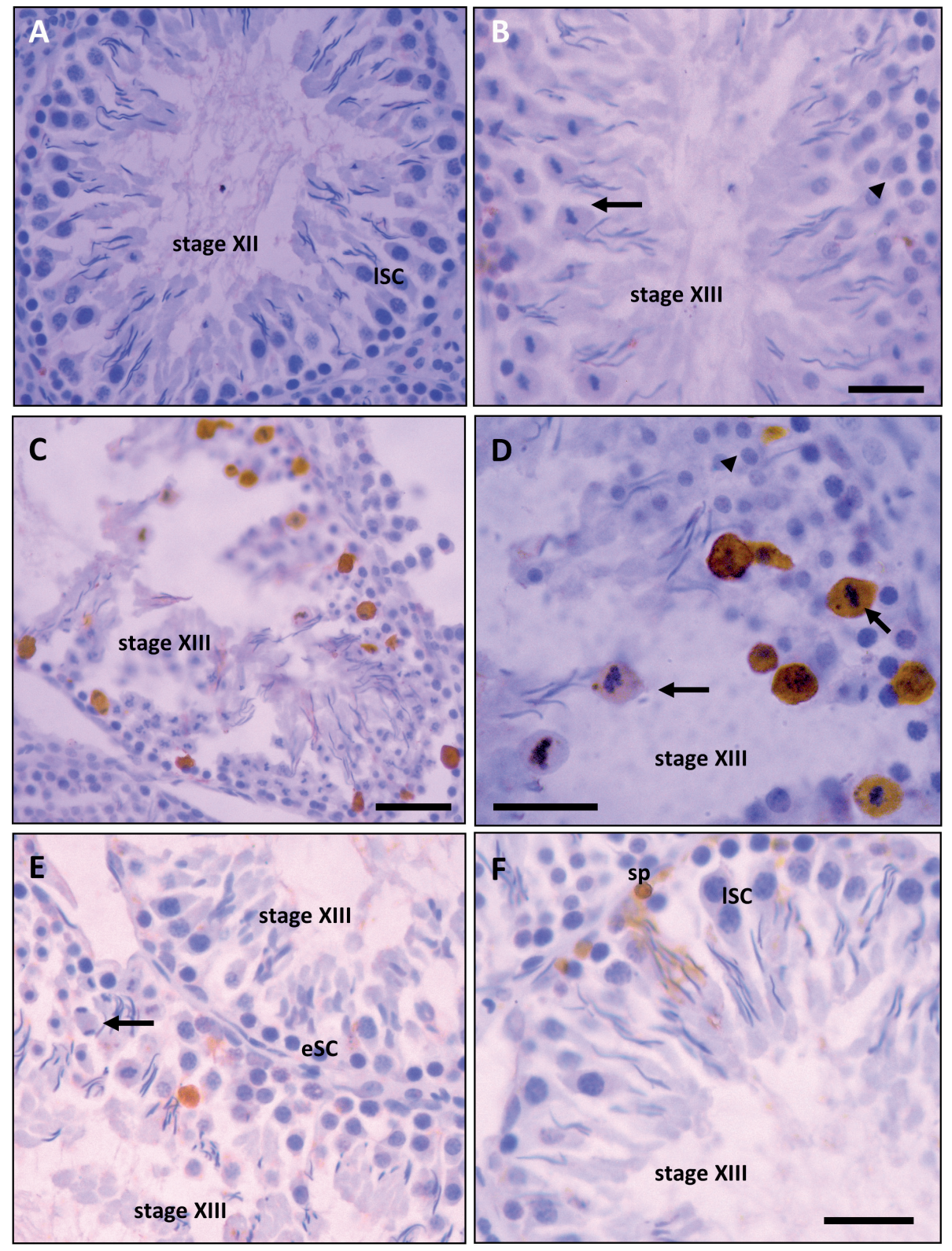

Figure 2. TUNEL stained testes sections show that UA exposure increases spermatocytes metaphase (stage XIII) apoptosis. Control testes stages XI-XII (A) and stage XIII (B); arrow shows normal metaphase cells, arrow-head shows 2ry spermatocytes. High frequency of apoptotic cells in UA-treated rats (stage XIII) (C, D); arrows show apoptotic dividing metaphase I cells. Stage XIII from TQ (E) and NAC (F) treated rats with no apoptotic metaphase cells. UA, uranyl acetate; NAC, Nacetylcysteine; TQ, thymoquinone; ISC, late spermatocytes; sp, spermatogonia; eSC, early spermatocytes. Scale bar, $10 \mu \mathrm{m}$. the appearance of degenerative and vascular pathological changes. On the other hand, TQ and NAC succeeded in attenuating the apoptotic and histopathological influences of UA on the testis without inducing any antioxidant effect.

GSH, the most abundant nonprotein thiol, is an essential player in establishment of redox balance, was reported to have radioprotection against DNA damage (Chatterjee 2013). Therefore, depletion of testicular GSH induces oxidative stress, especially when taken into consideration the high content of polyunsaturated fatty acids in testis (Periyakaruppan et al. 2007). In the present study, SOD activity was significantly inhibited in UA treated rats, which is consistent with the previously shown in erythrocytes (Bellés et al. 2007).
SOD level in the testis is a relatively high compared to other organs and its inhibition resulted in impaired sperm motility and hence infertility (Mruk et al. 2002; Garratt et al. 2013). This response has been attributed to down-regulation of SOD gene expression (Periyakaruppan et al. 2007). In the testis, NO displays a wide range of regulatory effects on blood flow, spermiogenesis, sperm viability, sperm motility, apoptosis, in addition to its cytoprotective functions (Kono et al. 2006). The significant reduction in the testicular NO level, observed in the present study, is in parallel with the decreased inducible NO gene expression following intratracheal instillation with DU particles in rats (Li et al. 2005). The non-significant changes in LPO levels relative to the control group in our 
study is consistent with that found in the renal cortex of UA exposed rat model (Kato et al. 1994). Selective differential sensitivity of enzymatic antioxidant to the inhibitory influence of DU on their activities could be a possible explanation (Linares et al. 2006; Lestaevel et al. 2015).

In the current model, no obvious persistent damage related $\gamma$-H2ax foci was found in spermatocytes, 25 days post exposure to a single dose of UA. However, a pronounced increase in metaphase I apoptosis was observed. In rats, 52 days are required for spermatogonia stem cells to differentiate into mature spermatozoa, and since the cycle duration in rats is 12.9 day (Clermont and Harvey 1965), thus in the current model, 25 days are enough for early spermatocytes to do the meiotic recombination and reach the $1^{\text {st }}$ meiotic division. Although some spermatocytes of the UA-treated group displayed $\gamma-\mathrm{H} 2 \mathrm{ax}$ foci that was insignificant and is not enough to propose that UA induced damage-related foci in spermatocytes persist for 25 days after exposure UA.

Previously, we and others have indicated that a single dose of ionizing radiation (doses of $0.5-1 \mathrm{~Gy}$, X- or gammairradiation) induced damage related foci persisted for several hours/few days post exposure (Ahmed et al. 2007, 2010, 2015; Paris et al. 2011). Considering that UA exposure has dual effects, cytotoxic and radioactive, it seems that UA induces genotoxic damage in germ cells during meiotic recombination, after spermatogonia stage, may persist but not for weeks. It is possible that damage is improperly repaired and thus activates the metaphase checkpoint when reaching metaphase I. Spermatogenesis was found to be arrested, even at very low doses of IR, that occurs primarily by inducing apoptosis in spermatogonia, with spermatogonia stem cells revealed elevated levels of DSBs for weeks after radiation (Grewenig et al. 2015). Here, there was insignificant increase in number of apoptotic spermatogonia in UA-treated group, probably for UA genotoxicity, although 25 days is a longer period to find an obvious effect on spermatogonia.

Failure of either TQ or NAC to enhance the redox sensitive balance in this study represents a major surprise owing to their well-known antioxidant activities. Nevertheless, evidences had been amassed from the literature denoting the diversity in the response patterns to TQ and NAC supplementation in relation to the differences in the studied doses and experimental models. TQ maintains its antioxidant property when utilized in low concentration and switches to be oxidative stress inducer when high concentrations were utilized, or even low concentrations in presence of transition metal ions as copper (Zubair et al. 2013). The antineoplastic property of TQ has been related to its ability to produce reactive oxidants
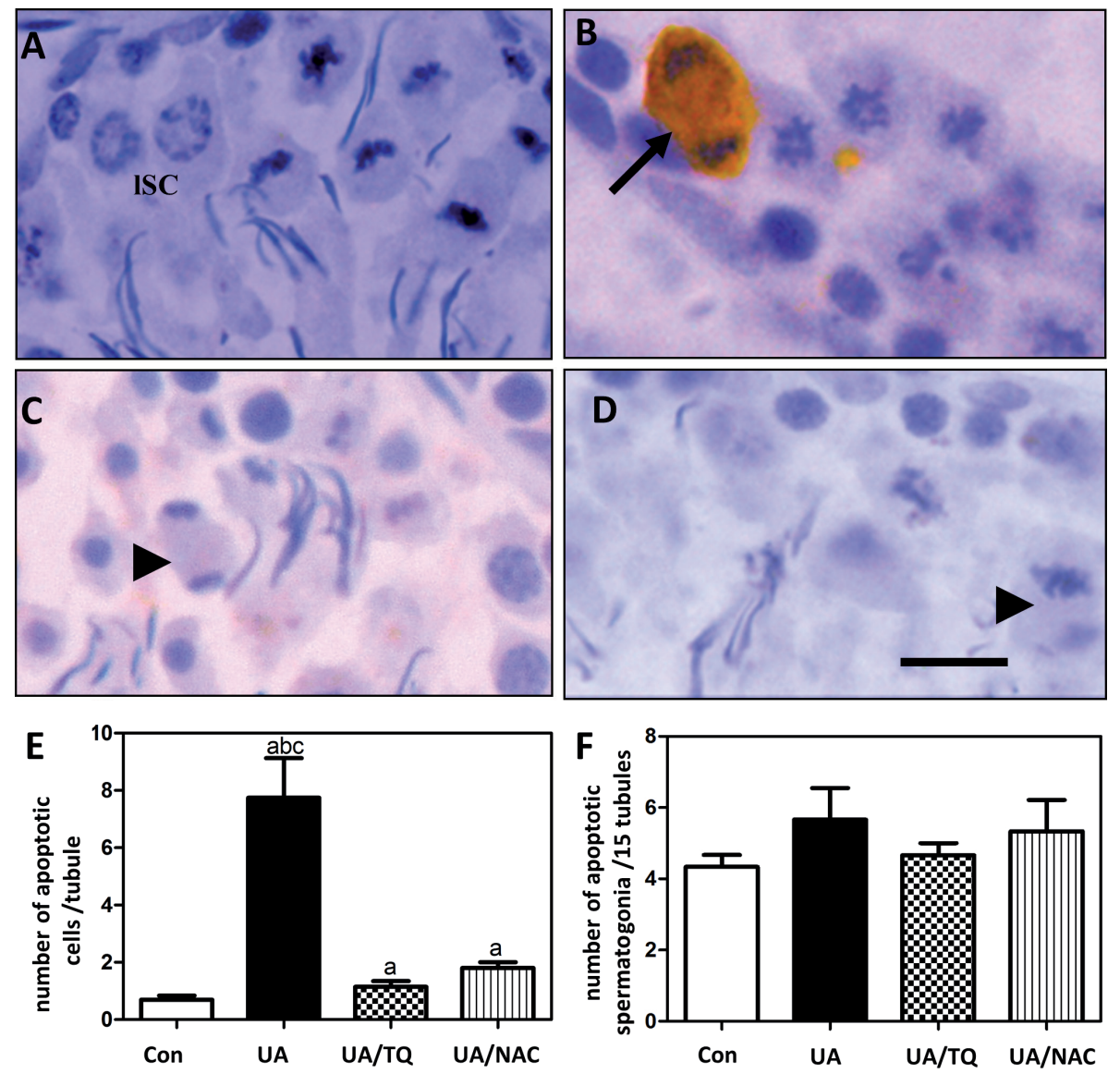

Figure 3. Immunostained testes sections show difficulties in segregation of homologous chromosomes only in UA-treated rats (B), but not in other treated groups, control (A), TQ (C) and NAC (D). E. A significant increase in metaphase apoptosis after UA exposure. F. An insignificant variation in number apoptotic spermatogonia from control and treated groups. Scale bar, $10 \mu \mathrm{m}$; ${ }^{\mathrm{a}, \mathrm{b}, \mathrm{c}} p<0.05$ compared with control, TQ and NAC groups, respectively (one-way ANOVA followed by Duncan posthoc test). UA, uranyl acetate; NAC, $\mathrm{N}$-acetylcysteine; TQ, thymoquinone; 1SC, late spermatocytes; arrow refers to apoptotic metaphase cell; arrow-head refers to dividing metaphase cell. 

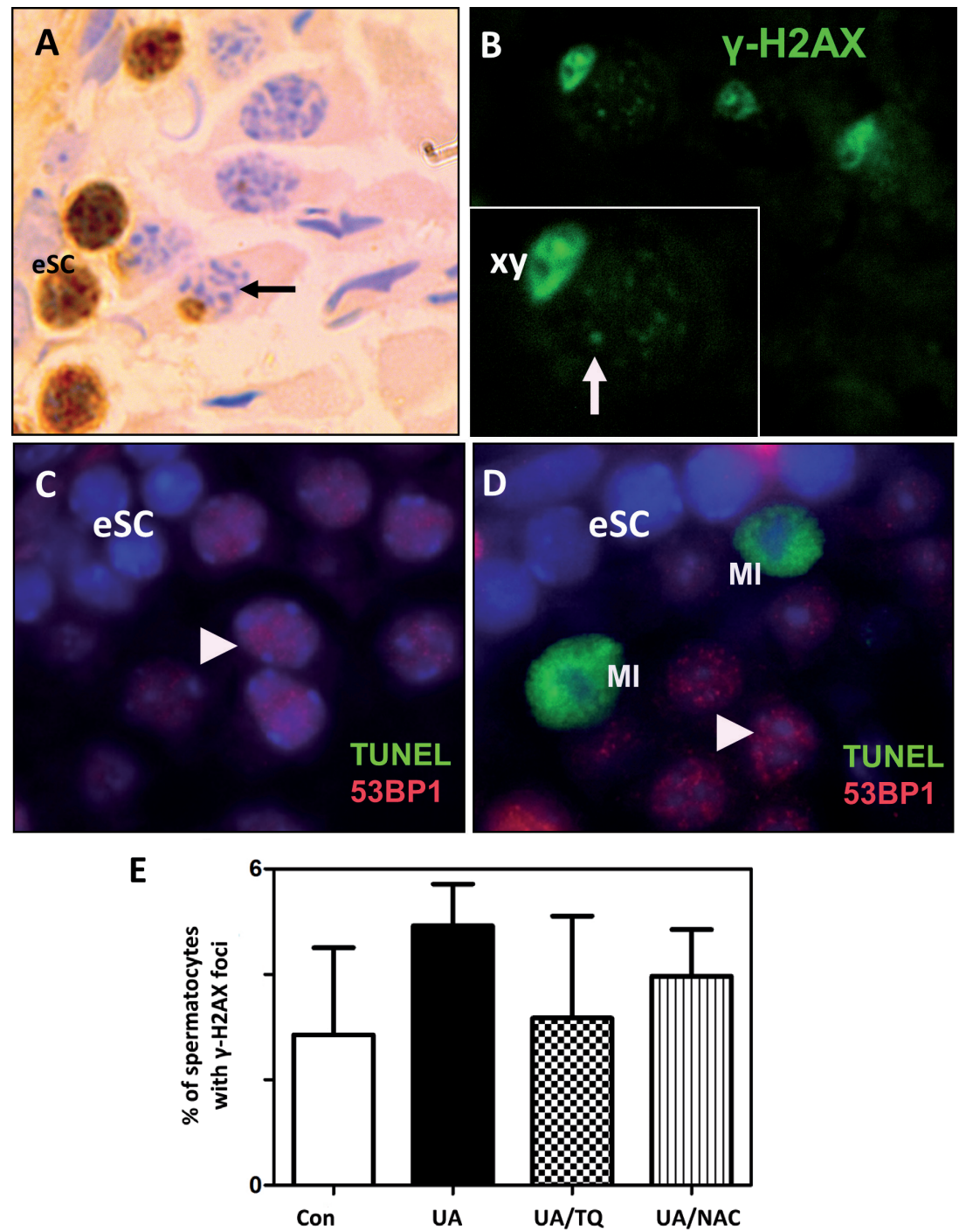

Figure 4. Immunostained testes sections show persistent damage-related foci in spermatocytes following UA exposure (A, B). Double immunostaining of 53BP1 and TUNEL assay (stage XIII) from control (C) and UA group (D). E. Insignificant increase in \% of apoptotic cells with foci in UA group relative to other treated groups. Scale bar, $10 \mu \mathrm{m}$; arrow refers to pachytene spermatocytes; arrow-head refers to 2ry spermatocytes; depicted area (in B) shows late spermatocyte with foci. UA, uranyl acetate; NAC, N-acetylcysteine; TQ, thymoquinone; eSC, early spermatocytes; MI, metaphase I cells.

and reduce GSH levels behaving as a pro-oxidant (Koka et al. 2010; Ashour et al. 2016; Taha et al. 2016). The same mechanistic factors were also involved in its antifungal effect on candida glabrata planktonic cells and biofilms (Almshawit and Macreadie 2017).

In the present study, TQ exhibited a marked cytoprotection in parallel with the findings in previous gamma irradiated models (Ahlatci et al. 2014; Guida et al. 2016). Also, TQ improved the testicular architecture against cadmium and titanium dioxide nanoparticles-induced toxicity in rats (Sayed et al. 2014; Hassanein and El-Amir 2017). Based on to the current measured parameters and analysis, we are unable to suppose the antioxidant role of TQ in this outcome, however TQ-anti-inflammatory and anti-apoptotic properties may be the main causative factors in the testicular cytoprotection by reducing the pro-inflammatory cytokines levels, and down-regulating PD-1, Bax and caspase- 3 expression and up-regulating Bcl-2 expression (Guida et al. 2016). Nevertheless, the partial alleviation in the testicular histopathological deteriorations and the reduction of apoptotic cells numbers following NAC supplementation indicates improvement at least on the cytological level which is corresponding to previous studies on gamma-irradiated liver and intestine (Sridharan and Shyamaladevi 2002; Mansour 
et al. 2008). This has been explained by inhibition of DNA fragmentation, down-regulation of caspase-3 expression and stimulation of radioprotective IL- $1 \alpha$ and $\beta$ and IL- 2 production (Mansour et al. 2008; Li et al. 2015).

\section{Conclusion}

An obvious disturbance in the testicular redox homeostasis in addition to histopathological and cytological alterations in testis was seen after 25 days of exposure to a single dose of UA. That was associated with a partial arrest of metaphase cells (metaphase I - metaphase II), which may explain why less spermatids and low fertility have been reported earlier after oral exposure to doses of UA (10-40 mg/kg/b.w.) for two weeks (Linares et al. 2005). The antioxidants, TQ and NAC attenuated the adverse effects of UA on the testicular microenvironment through anti-apoptotic and cytoprotective but not through antioxidant effects. Further studies are highly recommended to investigate UA toxicity within several hours and few days post-exposure, in addition to the protective effects of other natural compounds.

Acknowledgement. The Authors acknowledge Deanship of Scientific Research of King Faisal University, Saudi Arabia, for financial support under grant number 186062.

Conflict of interest. The authors declare that there are no conflicts of interests.

Author's contribution: H Waly, SMM Ragab, KMA Hassanein, NS Abou Khalil and EA Ahmed, designed the experiment, performed the practical work, analysed data and wrote the paper.

\section{References}

Ahlatci A, Kuzhan A, Taysi S, Demirtas OC, Alkis HE, Tarakcioglu M, Demirci A, Caglayan D, Saricicek E, Cinar K (2014): Radiation-modifying abilities of Nigella sativa and thymoquinone on radiation-induced nitrosative stress in the brain tissue. Phytomedicine 21, 740-744

https://doi.org/10.1016/j.phymed.2013.10.023

Ahmed EA, van der Vaart A, Barten A, Kal HB, Chen J, Lou Z, Minter-Dykhouse K, Bartkova J, Bartek J, de Boer P, de Rooij DG (2007): Differences in DNA double strand breaks repair in male germ cell types: lessons learned from a differential expression of Mdc1 and 53BP1. DNA Repair (Amst) 6, $1243-1254$ https://doi.org/10.1016/j.dnarep.2007.02.011

Ahmed EA, Philippens ME, Kal HB, de Rooij DG, de Boer P (2010): Genetic probing of homologous recombination and nonhomologous end joining during meiotic prophase in irradiated mouse spermatocytes. Mutat. Res. 688, 12-18 https://doi.org/10.1016/j.mrfmmm.2010.02.004
Ahmed EA, Sfeir A, Takai H, Scherthan H (2013): Ku70 and nonhomologous end joining protect testicular cells from DNA damage. J. Cell. Sci. 126, 3095-3104 https://doi.org/10.1242/jcs.122788

Ahmed EA, Scherthan H, de Rooij DG (2015): DNA double strand break response and limited repair capacity in mouse elongated spermatids. Int. J. Mol. Sci. 16, 29923-29935 https://doi.org/10.3390/ijms161226214

Ahmed EA, Velaz E, Rosemann M, Gilbertz KP, Scherthan H (2017): DNA repair kinetics in SCID mice Sertoli cells and DNA-PKcs-deficient mouse embryonic fibroblasts. Chromosoma 126, 287-298

https://doi.org/10.1007/s00412-016-0590-9

Aitken RJ, Roman SD (2008): Antioxidant systems and oxidative stress in the testes. Oxid. Med. Cell. Longev. 1, 15-24 https://doi.org/10.4161/oxim.1.1.6843

Almshawit H, Macreadie I (2017): Fungicidal effect of thymoquinone involves generation of oxidative stress in Candida glabrata. Microbiol. Res. 195, 81-88 https://doi.org/10.1016/j.micres.2016.11.008

Arfsten DP, Still KR, Wilfong ER, Johnson EW, McInturf SM, Eggers JS, Schaeffer DJ, Bekkedal MV (2009): Two-generation reproductive toxicity study of implanted depleted uranium (DU) in CD rats. J. Toxicol. Environ. Health, Part A 72, 410-427

Asghari MH, Saeidnia S, Rezvanfar MA, Abdollahi MI (2015): A systematic review of the molecular mechanisms of uranium -induced reproductive toxicity. Allergy Drug Targets 14, 67-76 https://doi.org/10.2174/1871528114666160105112441

Ashour AE, Ahmed AF, Kumar A, Zoheir KMA, Aboul-Soud MA, Ahmad SF, Attia SM, Abd-Allah AR, Cheryan VT, Rishi AK (2016): Thymoquinone inhibits growth of human medulloblastoma cells by inducing oxidative stress and caspase-dependent apoptosis while suppressing NF- $\mathrm{kB}$ signaling and IL-8 expression. Mol. Cell. Biochem. 416, 141-155 https://doi.org/10.1007/s11010-016-2703-4

Azzam EI, Jay-Gerin JP, Pain D (2012): Ionizing radiation-induced metabolic oxidative stress and prolonged cellinjury. Cancer Lett. 327, 48-60 https://doi.org/10.1016/j.canlet.2011.12.012

Badr G, Mahmoud MH, Farhat K, Waly H, Al-Abdin OZ, Rabah DM (2013): Maternal supplementation of diabetic mice with thymoquinone protects their offspring from abnormal obesity and diabetes by modulating their lipid profile and free radical production and restoring lymphocyte proliferation via PI3K/ AKT signaling. Lipids Health Dis. 12, 12-37 https://doi.org/10.1186/1476-511X-12-37

Barber DS, Ehrich MF, Jortner BS (2005): The effect of stress on the temporal and regional distribution of uranium in rat brain after acute uranyl acetate exposure. J. Toxicol. Environ. Health, Part A 68, 99-111 https://doi.org/10.1080/15287390590885910

Bauché F, Fouchard MH, Jégou B (1994): Antioxidant system in rat testicular cells. FEBS Lett. 349, 392-396 https://doi.org/10.1016/0014-5793(94)00709-8

Bellés M, Linares V, Luisa Albina M, Sirvent J, Sánchez DJ, Domingo JL (2007): Melatonin reduces uranium-induced nephrotoxicity in rats. J. Pineal. Res. 43, 87-95 https://doi.org/10.1111/j.1600-079X.2007.00447.x 
Beutler E, Duron O, Kelly BM (1963): Improved method for the determination of blood glutathione. J. Lab. Clin. Med. 61, 882-888

Bleise A, Danesi PR, Burkart W (2003): Properties, use and health effects of depleted uranium (DU): a general overview. J. Environ. Radioact. 64, 93-112 https://doi.org/10.1016/S0265-931X(02)00041-3

Briner W (2010): The toxicity of depleted uranium. Int. J. Environ. Res. Public Health 7, 303-313 https://doi.org/10.3390/ijerph7010303

Clermont Y, Harvey SC (1965): Duration of the cycle of the seminiferous epithelium of normal, hypophysectomized and hypophysectomized-hormone treated albino rats. Endocrinology $76,80-89$ https://doi.org/10.1210/endo-76-1-80

Chatterjee A (2013): Reduced glutathione: a radioprotector or a modulator of DNA-repair activity? Nutrients 5, 525-542 https://doi.org/10.3390/nu5020525

Demİrel C, Kilçiksiz S, Ay OI, Gürgül S, Erdal N (2009): Effect of $\mathrm{N}$-acetylcysteine on radiation-induced genotoxicity and cytotoxicity in rat bone marrow. J. Radiat. Res. 50, 43-50 https://doi.org/10.1269/jrr.08066

Di Lella LA, Nannoni F, Protano G, Riccobono F (2005): Uranium contents and $235 \mathrm{U} / 238 \mathrm{U}$ atom ratios in soil and earthworms in western Kosovo after the 1999 war. Sci. Total Environ. 337, $109-118$ https://doi.org/10.1016/j.scitotenv.2004.07.001

Ding AH, Nathan CF, Stuehr DJ (1988): Release of reactive nitrogen intermediates and reactive oxygen intermediates from mouse peritoneal macrophages. Comparison of activating cytokines and evidence for independent production. J. Immunol. 141, 2407-2412

Dublineau I, Souidi M, Gueguen Y, Lestaevel P, Bertho JM, Manens L, Delissen O, Grison S, Paulard A, Monin A, et al. (2014): Unexpected lack of deleterious effects of uranium on physiological systems following a chronic oral intake in adult rat. Biomed. Res. Int. 2014, 181989 https://doi.org/10.1155/2014/181989

Fouad AA, Jresat I (2015): Thymoquinone therapy abrogates toxic effect of cadmium on rat testes. J. Andrologia 47, 417-426 https://doi.org/10.1111/and.12281

Garratt M, Bathgate R, de Graaf SP, Brooks RC (2013): Copper-zinc superoxide dismutase deficiency impairs sperm motility and in vivo fertility. Reproduction 146, 297-304 https://doi.org/10.1530/REP-13-0229

Grignard E, Guéguen Y, Grison S, Lobaccaro JA, Gourmelon P, Souidi M (2008): Contamination with depleted or enriched uranium differently affects steroidogenesis metabolism in rat. Int. J. Toxicol. 27, 323-328 https://doi.org/10.1080/10915810802367057

Grewenig A, Schuler N, Rübe CE (2015): Persistent DNA damage in spermatogonial stem cells after fractionated low-dose irradiation of testicular tissue. Int. J. Radiat. Oncol. Biol. Phys. 92, 1123-1131

https://doi.org/10.1016/j.ijrobp.2015.04.033

Guida MS, El-Aal AA, Kafafy Y, Salama SF, Badr BM, Badr G (2016): Thymoquinone rescues $T$ lymphocytes from gamma irradiation-induced apoptosis and exhaustion by modulating pro-inflammatory cytokine levels and PD-1, Bax, and Bcl-2 signaling. Cell. Physiol. Biochem. 38, 786-800 https://doi.org/10.1159/000443034

Hao Y, Liu C, Huang J, Gu Y, Li H, Wang W, Li R (2016): Ghrelin protects against depleted uranium-induced apoptosis of MC3T3-E1 cells through oxidative stress-mediated p38mitogen-activated protein kinase pathway. Toxicol. Appl. Pharmacol. 290, 116-125

https://doi.org/10.1016/j.taap.2015.10.022

Hassanein KMA, El-Amir YO (2017): Protective effects of thymoquinone and avenanthramides on titanium dioxide nanoparticles induced toxicity in Sprague-Dawley rats. Pathol. Res. Pract. 213, 13-22 https://doi.org/10.1016/j.prp.2016.08.002

Hossein Asghari M, Saeidnia S, Amin Rezvanfar M, Abdollahi M (2015): A systematic review of the molecular mechanisms of uranium-induced reproductive toxicity. Inflamm. Allergy Drug Targets 14, 67-76

https://doi.org/10.2174/1871528114666160105112441

Jin B, Zheng R, Peng R, Chu S (2016): Synthesis of new bis (3-hydroxy-4-pyridinone) ligands as chelating agents for uranyl complexation. Molecules 21, 299-310 https://doi.org/10.3390/molecules21030299

Kato A, Hishida A, Nakajima T (1994): Effects of oxygen free radical scavengers on uranium-induced acute renal failure in rats. Free Radic. Biol. Med. 16, 855-859 https://doi.org/10.1016/0891-5849(94)90204-6

Khan S, Adhikari JS, Rizvi MA, Chaudhury NK (2015): Radioprotective potential of melatonin against $60 \mathrm{Co} \gamma$-ray-induced testicular injury in male C57BL/6 mice. J. Biom. Sci. 22, 61-75 https://doi.org/10.1186/s12929-015-0156-9

Kilciksiz S, Demirel C, Erdal N, Gürgül S, TamerL, Ayaz L (2008): The effect of $\mathrm{N}$-acetylcysteine on biomarkers for radiationinduced oxidative damage in a rat model. Acta Med. Okayama 62, 403-409

Koka PS, Mondal D, Schultz M, Abdel-Mageed AB, Agrawal KC (2010): Studies on molecular mechanisms of growth inhibitory effects of thymoquinone against prostate cancer cells: role of reactive oxygen species. Exp. Biol. Med. 235, 751-760 https://doi.org/10.1258/ebm.2010.009369

Kono T, Saito M, Kinoshita Y, Satoh I, Shinbori C, Satoh K (2006): Real-time monitoring of nitric oxide and blood flow during ischemia-reperfusion in the rat testis. Mol. Cell. Biochem. 286, 139-145 https://doi.org/10.1007/s11010-005-9105-3

Kundu JI, Kim DH, Kundu JK, Chun KS (2014): Thymoquinone induces heme oxygenase-1 expression in $\mathrm{HaCaT}$ cells via $\mathrm{Nrf} 2 /$ ARE activation: Akt and AMPKa as upstream targets. Food Chem. Toxicol. 65, 18-26 https://doi.org/10.1016/j.fct.2013.12.015

Legendre A, Elie C, Ramambason C, Manens L, SouidiM, Froment P, Tack K (2016): Endocrine effects of lifelong exposure to low-dose depleted uranium on testicular functions in adult rat. Toxicology $368,58-68$ https://doi.org/10.1016/j.tox.2016.08.014

Lestaevel P, Dhieux B, Delissen O, Benderitter M, Aigueperse J (2015): Uranium modifies or not behavior and antioxidant status in the hippocampus of rats exposed since birth. J. Toxicol. Sci. 40, 99-107 https://doi.org/10.2131/jts.40.99 
Li J, Meng Z, Zhang G, Xing Y, Feng L, Fan S, Fan F, Buren B, Liu Q (2015): $\mathrm{N}$-acetylcysteine relieves oxidative stress and protects hippocampus of rat from radiation-induced apoptosis by inhibiting caspase-3. Biomed. Pharmacother. 70, 1-6 https://doi.org/10.1016/j.biopha.2014.12.029

Li JS, Zhang H, Wang HR, Yang F, Chne J (2005): Inducible nitric oxide synthase gene expression in the testis of rats instilled with depleted uranium particles. Zhonghua Nan Ke Xue 11, 655-657 (in Chinese)

Li R, Ren J, Liu J, Ai G, Xu H, Su Y, Cheng T, Leng Y (2009): Effect of long-term depleted uranium ingestion on testosterone production and the expression of StAR and P450scc mRNAs in rats. Chin. J. Radiol. Med. Prot. 29, 13-16

Linares VI, Albina ML, Bellés M, Mayayo E, Sánchez DJ, Domingo JL (2005): Combined action of uranium and stress in the rat. II. Effects on male reproduction. Toxicol. Lett. 158, 186-195 https://doi.org/10.1016/j.toxlet.2005.03.015

Linares V, Bellés M, Albina ML, Sirvent JJ, SánchezDJ, Domingo JL (2006): Assessment of the pro-oxidant activity of uranium in kidney and testis of rats. Toxicol. Lett. 167, 152-161 https://doi.org/10.1016/j.toxlet.2006.09.004

Llobet JM, Sirvent JJ, Ortega A, Domingo J (1991): Influence of chronic exposure to uranium on male reproduction in mice. Fundam. Appl. Toxicol. 16, 821-829 https://doi.org/10.1093/toxsci/16.4.821

Lowry OL, Rosebrough NJ, Farr AL, Randall RJ (1951) Protein determination with the Folin phenol reaction. J. Biol. Chem. 93, 265-273

Mansour HH, Hafez HF, Fahmy NM, Hanafi N (2008): Protective effect of $\mathrm{N}$-acetylcysteine against radiation induced DNA damage and hepatic toxicity in rats. Biochem. Pharmacol. $75,773-780$ https://doi.org/10.1016/j.bcp.2007.09.018

Marzban M, Anjamshoa M, Jafari P, Masoumi H, Ahadi R, Fatehi D (2017): Effects of gamma rays on rat testis tissue according to the morphological parameters and immunohistochemistry: radioprotective role of silymarin. Electron. Physician 9, 4524 https://doi.org/10.19082/4524

Misra HP, Fridovich I (1972): The role of superoxide anion in the autoxidation of epinephrine and a simple assay for superoxide dismutase. J. Biol. Chem. 247, 3170-3175

Mruk DD, Silvestrini B, Mo MY, Cheng CY (2002): Antioxidant superoxide dismutase-a review: its function, regulation in the testis, and role in male fertility. Contraception $\mathbf{6 5}, 305-311$ https://doi.org/10.1016/S0010-7824(01)00320-1

Ohkawa H, Ohishi N, Yagi K (1979): Assay for lipid peroxides in animal tissues by thiobarbituric acid reaction. Anal. Biochem. 95, 351-358 https://doi.org/10.1016/0003-2697(79)90738-3

Paris L, Cordelli E, Eleuteri P, Grollino MG, Pasquali E, Ranaldi R, Meschini R, Pacchierotti F (2011): Kinetics of gamma-H2AX induction and removal in bone marrow and testicular cells of mice after X-ray irradiation. Mutagenesis 26, 563-572

https://doi.org/10.1093/mutage/ger017

Periyakaruppan A, Kumar F, Sarkar S, Sharma CS, Ramesh GT (2007): Uranium induces oxidative stress in lung epithelial cells. Arch. Toxicol. 81, 389-395 https://doi.org/10.1007/s00204-006-0167-0

Prakash A, Kumar A (2009): Effect of N-acetyl cysteine against aluminium-induced cognitive dysfunction and oxidative damage in rats. Basic Clin. Pharmacol. Toxicol. 105, 98-104 https://doi.org/10.1111/j.1742-7843.2009.00404.x

Russell LD, Ettlin RA, Hikim APS, Clegg ED (1990): Staging for laboratory species. In: Histological and Histopathological Evaluation of the Testis. pp. 62-194, Cache River Press, Clearwater, FL

Sayed MM, Hassanein KM, Senosy W (2014): Protective effects of thymoquinone and l-cysteine on cadmium-induced reproductive toxicity in rats. Toxicol. Rep. 1, 612-620 https://doi.org/10.1016/j.toxrep.2014.08.001

Sridharan S, Shyamaladevi CS (2002): Protective effect of Nacetylcysteine against gamma ray induced damages in ratsbiochemical evaluations. Indian J. Exper. Boil. 40, 181-186

Swami S, Shrivastava R (2016): Acyclic and macrocyclic Schiff base-based chelating ligands for uranyl ion (Uo22+) complexation. Res. Methodol. Chem. Sci. Expe. Theor. Approach 187-196. Apple Academic press\&CRC press, Taylor and Frances group, USA

Szumiel I (2015): Ionizing radiation-induced oxidative stress, epigenetic changes and genomic instability: the pivotal role of mitochondria. Int. J. Radiat. Biol. 91, 1-12 https://doi.org/10.3109/09553002.2014.934929

Taha MM, Sheikh BY, Salim L. Z, Mohan S, Khan A, Kamalidehghan B, Ahmadipour F, Abdelwahab SI (2016) Thymoquinone induces apoptosis and increase ROS in ovarian cancer cell line. Cell. Mol. Biol. 62, 97-101

Tüfek NH, Altulkaynak MK, Altulkaynak ME, Kaplan S (2015): Effects of thymoquinone on testicular structure and sperm production in male obese rats. J. Syst. Biol. Reprod. Med. 61, 194-204 https://doi.org/10.3109/19396368.2015.1044135

Yi JH, Hazell AS (2005): N-acetylcysteine attenuates early induction of heme oxygenase-1 following traumatic brain injury. Brain Res. 1033, 13-19 https://doi.org/10.1016/j.brainres.2004.10.055

Zubair H, Khan HY, Sohail A, Azim S, UllahMF, Ahmad A, Sarkar FH, Hadi SM (2013): Redox cycling of endogenous copper by thymoquinone leads to ROS-mediated DNA breakage and consequent cell death: putative anticancer mechanism of antioxidants. Cell Death Dis. 4, e660 https://doi.org/10.1038/cddis.2013.172

Received: May 6, 2018

Final version accepted: October 24, 2018

First published online: December 14, 2018 